\title{
EL PINTOR ALONSO DE NARVÁEZ Y LA DEVOCIÓN A LA VIRGEN DE CHIQUINQUIRÁ. NUEVOS APORTES BIOGRÁFICOS
}

\author{
Guadalupe Romero Sánchez \\ Universidad de Granada
}

Data recepción: 2018/11/10

Data aceptación: 2019/05/24

Contacto autora: guadalupers@ugr.es

ORCID: https://orcid.org/0000-0003-3865-3579

\section{RESUMEN}

El primer pintor europeo del que tenemos noticias en territorio neogranadino es el sevillano Alonso de Narváez, establecido en Tunja pocos años después de haberse fundado la ciudad en 1539. Sobre su vida apenas hay referencias, a pesar de ser el autor de la Virgen de Chiquinquirá, cuya fama y devoción pronto traspasará los límites de la Audiencia y de la que daremos cuenta a lo largo del texto. En este artículo reconstruimos el árbol genealógico de Narváez, así como otros aspectos relacionados con su biografía, su labor como artista y sus lazos sociales y de vecindad. Para ello nos hemos servido de su testamento, de varios pleitos, de censos de población, memoriales y otros documentos oficiales.

Palabras clave: Alonso de Narváez, Ana de Prado, Siglo XVI, Nuestra Señora del Rosario de Chiquinquirá, Tunja

\section{ABSTRACT}

The first European painter we have word of in the New Kingdom of Granada is the Sevillian artist Alonso de Narváez, who settled in Tunja a few years after the city's foundation in 1539. Though little is known about his life, we do know that he painted the Virgin of Chiquinquirá, which attracted fame and devotion that would soon extend beyond the limits of the Royal Audiencia, as we will show throughout the text. In this article we reconstruct Narváez's family tree and other aspects relating to his life, his work as an artist and his social and community ties. In doing so, we have referred to his will, various court papers, population censuses, memorial pieces, and other official documents.

Keywords: Alonso de Narváez, Ana de Prado, 16th century, Our Lady of the Rosary of Chiquinquirá, Tunja

\section{Introducción}

En 1539 Gonzalo Suárez Rendón fundaba la ciudad de Tunja. Al tiempo se proyectaba su trazado en una cuadrícula perfecta en torno a la plaza central. Iglesias, conventos y grandes mansiones con destacadas portadas de piedras blasonadas se levantaron a lo largo de esta centuria dando forma a una ciudad que fue llamada por el investigador Morales Folguera la "Atenas del Renacimiento en el Nuevo Reino de Granada"

El ambiente culto y refinado de la ciudad atrajo pronto a numerosos artistas. El primer pintor conocido en la historia artística neogranadina, que se estableció en Tunja poco tiempo después de 


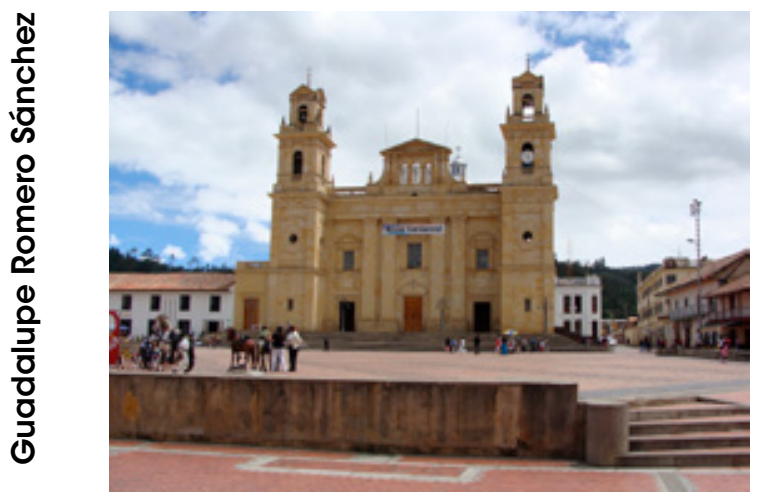

Fig. 1. Basílica de Nuestra Señora del Rosario. Chiquinquirá. Departamento de Boyacá, Colombia. Fotografía: autora

su fundación, fue Alonso de Narváez, natural de la localidad sevillana de Alcalá de Guadaíra, autor del lienzo de Nuestra Señora del Rosario de Chiquinquiráa. A él le siguen otros artistas, por citar algunos ejemplos podemos advertir la participación del pintor Juan Pérez en 1587 en la realización de la Capilla del Rosario de Tunja, como autor de la Virgen de la Contemplación para la puerta del Sagrario3. Ese mismo año llegaría el pintor romano Angelino Medoro al que se unió el milanés Francisco del $\mathrm{PozO}^{4}$, dejando una importantísima obra pictórica renacentista, mucho más abundante en el caso de Medoro5. Ya en el siglo XVII contamos con el sevillano Bartolomé de Figueroa "el viejo" (iniciador de una importante saga de pintores), así como con Antonio Acero de la Cruz, Gregorio Vásquez de Arce y Ceballos, Alonso Fernández de Heredia o Pedro de Aguirre, lo que coloca a Tunja entre las ciudades más importantes del Nuevo Reino a nivel artístico.

Sobre la mayoría de estos pintores la producción bibliográfica es muy extensa, lo que no ocurre con Alonso de Narváez. De hecho, son escasísimos los datos que se conocen sobre su vida y obra, aunque hace algunos años pudimos profundizar en ellos atendiendo a los datos que él mismo nos proporcionó en su testamento ${ }^{6}$. Por contrapartida la historiografía ha sido muy fértil al tratar sobre su única obra conocida, acrecentada desde muy temprano por la fama de milagrosa. Así, muchos cronistas e investigadores han tratado sobre el lienzo de Chiquinquirá desde muy diferentes posiciones y con distintas finalidades, centrándose en el estudio de la obra en sí, en su historia, en los hechos extraordinarios atribuidos a su intermediación, en su iconografía y errores compositivos o en su estado de conservación, sin prestar el menor interés por averiguar aspectos relacionados con su artífice o su círculo social.

Esta será nuestra labor, intentar recuperar datos que aunque escasos y procedentes de fuentes o documentos dispersos, puedan aportar algo de luz sobre la biografía de este artista, atendiendo también a sus lazos familiares y de vecindad en la ciudad de Tunja. Para ello tomamos como primeras referencias las crónicas escritas entre los siglos XVII y XVIII donde se mencionan aspectos muy interesantes en torno al encargo de la obra y el milagro de su renovación. Posteriormente nos detendremos de manera muy breve en comprobar cómo se propagó el culto a la Virgen de Chiquinquirá no solo entre los habitantes tunjanos sino también entre los indios reducidos en los pueblos de la región, este hecho aunque se aparta de nuestro cometido es muy importante por las implicaciones que tiene y que no hemos querido dejar pasar. En un tercer apartado nos centraremos en reconstruir la biografía de Narváez a través de la creación de su árbol genealógico y de su actividad profesional en la ciudad, para concluir con el análisis del censo poblacional de Tunja a comienzos del siglo XVII donde aparecerán a manera de cierre todos los personajes reseñados, perfilándose lazos de vecindad que consideramos fundamentales como base para futuras investigaciones (fig. 1).

\section{Agentes implicados en el encargo del lienzo y el milagro de su renovación}

2.1. El encargo del lienzo milagroso: Antonio de Santana y Andrés Jadraque

Debemos partir inexorablemente de la obra de Tobar y Buendía editada en Madrid en 16947, en ella se narra cómo uno de los primeros conquistadores en llegar al Nuevo Reino de Granada fue Antonio de Santana, a quien la Corona en compensación por los servicios militares prestados concedió el disfrute de las encomiendas de los pueblos de indios de Suta y de Chiquinquirá, distantes ocho leguas uno de otro y pertenecientes al término territorial de la ciudad de Tunja. En los aposentos que Santana poseyó posteriormente en Suta ordenaría poco tiempo después levantar: 
... una capilla pequeña de vara en tierra y paja, y con deseo, de poner en ella una Imagen de la Madre de Dios del Rosario, se fue a la ciudad de Tunja, que dista del pueblo de Suta, catorce leguas, y mandó a Alonso de Narváez, que era el Pintor, que había en dicha ciudad, que le pintara una Imagen de Nuestra Señora del Rosario, en una Manta de Algodón (que era el lienzo, que había en aquel tiempo)'.

Según refiere el escribano de la Real Audiencia Juan Flórez de Ocáriz en sus Genealogías editadas en Madrid en 1674, Santana, al que reseña como Antón, llegó al Nuevo Reino de Granada en 1541 junto al Gobernador Gerónimo Lebrón y en compañía de su hermano Hernando․ Tras su muerte por no tener hijos le sucedería en sus encomiendas su mujer Catalina García de Irlos, dejando constancia de que tras el fallecimiento de ella se les otorgase a su sobrino Francisco de Aguilar Santana10, el hijo de Hernando, que llegaría con posterioridad"1.

Según algunos investigadores fue en 1560 cuando Santana fue beneficiado con la encomienda de indios de Suta, territorio donde ya habían incursionado los dominicos, custodios hoy de la imagen, entre 1555 y $1^{1558^{12}}$, sin embargo, en un interrogatorio que hemos localizado en el Archivo General de la Nación de Colombia y que realiza uno de los oidores y visitadores de la audiencia santafereña al propio Santana, que se presenta también como Antón, podemos situarlo algunos años antes como encomendero. Así, en virtud de las inspecciones llevadas a cabo en agosto de 1560 en algunos de los pueblos de indios de la zona entre los que se encontraba Suta, el propio encomendero afirmará que era poseedor de ese título por ejecutoria de la Real Chancillería del Nuevo Reino y que disfrutaba de él desde hacía 4 años y medio aproximadamente por lo que éste debió concederse hacia 1555 , estando establecido ya para entonces en la ciudad de Tunja ${ }^{13}$.

En la casa de Antonio de Santana vivió Andrés Jadraque, religioso español que había llegado a la región en $1550^{14}$. Según expone fray Alonso de Zamora en 1701 era «lego de gran virtud y deseo de la conversión de los indios» ${ }^{15}$. A él le comunicaría el encomendero su deseo de poner una imagen de la Virgen del Rosario en el oratorio de su casa, donde algunas veces decían misa

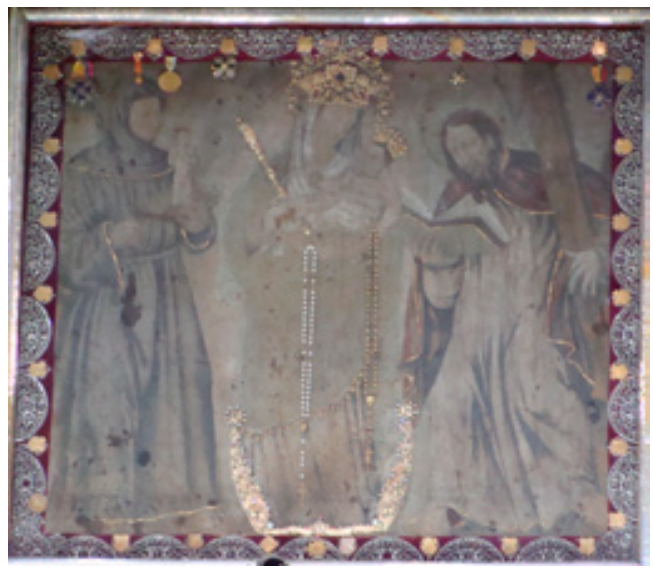

Fig. 2. Narváez, Alonso de. Nuestra Señora de Chiquinquirá, mediados del siglo XVI. Basílica de Nuestra Señora del Rosario. Chiquinquirá, Departamento de Boyacá, Colombia. Fotografía: autora

los religiosos que se encontraban catequizando a los naturales del partido, encargándole a este fraile buscar quien lo pintara. Con este encargo, prosigue Zamora, Jadraque marcharía a la ciudad de Tunja y trataría con Alonso de Narváez sobre su materialización, siendo el mismo fraile quien, una vez ejecutado el cuadro, lo llevaría personalmente a la estancia de Santana quien agradado por el resultado ordenaría ponerlo en su capilla.

Como puede advertirse entre Tobar y Buendía y Zamora hay dos versiones diferentes del encargo de la obra, aspecto que no será el único en el que difieran pues en la concreción de la iconografía del lienzo también presentan grandes divergencias ${ }^{16}$. Así, para Tobar y Buendía la decisión final en la elección de San Antonio de Padua y San Andrés como los santos que acompañan a la Virgen en el lienzo y que se ejecutaron a derecha e izquierda de esta, respectivamente, partiría del propio Santana quien afirma ser el ideólogo intelectual de la imagen no interviniendo el artista más que para plasmar su idea fielmente, mientras que para Zamora sería Jadraque junto con Narváez quienes decidieron sobre este asunto, debido a una pretendida motivación derivada de la forma de la manta de algodón usada como lienzo ${ }^{17}$.

El papel protagonista de Antonio de Santana o Andrés Jadraque en la definición final de la obra y en la elección de sus personajes, San 


\section{CUADRO GENEALÓGICO DE ANTONIO DE SANTANA}

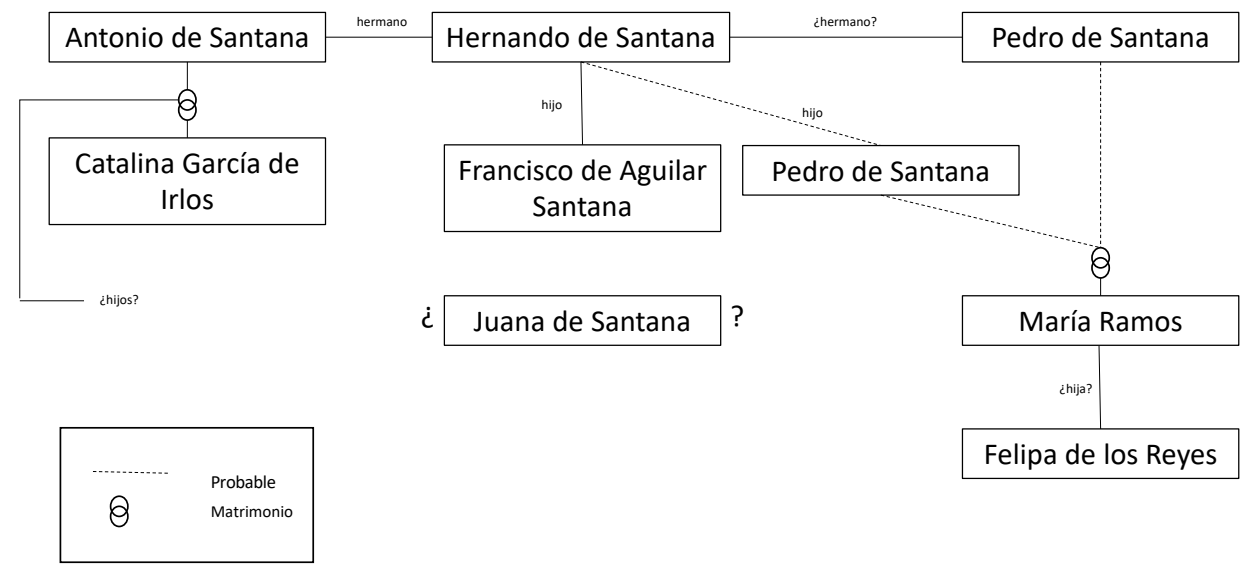

Fig. 3. Cuadro genealógico del conquistador Antonio de Santana. Elaboración propia

Antonio de Padua y San Andrés que según vemos serían sus santos homónimos y protectores, es muy cuestionable. A nivel iconográfico se ha debatido ampliamente habiendo dudas sustanciales incluso de si en origen representaría a una Virgen del Rosario o si este elemento definitorio de su imagen le fue colocado al lienzo como un postizo tras el establecimiento de los dominicos en la zona (fig. 2).

No obstante, a nivel de conjunto y sin entrar en los consabidos errores de representación presentes en la obra y achacados a Narváez por su pretendida escasa formación ${ }^{18}$, el debate continúa pues las imágenes de la Virgen, San Antonio y San Andrés se presentan estáticas y sin aparente relación lo que se ha visto como ejemplo de una "Sacra Conversazione" entendida esta como reunión, pudiendo tener como modelo la representación de estatuas colocadas en hilera de algún retablo portátil del siglo $\mathrm{XV} \mathbf{l}^{19}$. Este elemento no sería extraño en la Tunja contemporánea pues las necesidades de evangelización en los pueblos de indios de la provincia y la escasez de objetos en los templos y de religiosos permanentes haría que en un primer momento los curas doctrineros se vieran obligados a prestar servicio en varias poblaciones debiendo llevar consigo los elementos básicos para la liturgia y catequización, siendo los retablos portátiles necesarios y a veces imprescindibles.

Ahora bien como ya pudimos averiguar Alonso de Narváez era además escultor ${ }^{20}$ y como artista debió estar relacionado con mercaderes de la ciudad para la venta de sus obras en sus respectivas tiendas y la recepción de posibles encargos, por lo que no sería extraño que en algún momento entrara contacto con algunos de estos objetos y los conociera de primera mano. No obstante, tampoco debemos obviar la influencia que los grabados europeos podrían haber ejercido en sus composiciones pictóricas de Narváez pues, al igual que ocurría en el resto del continente, las estampas son una fuente principal de inspiración y ejecución de obras, siendo esta teoría la más aceptada en algunas de las investigaciones más destacadas en el debate sobre la definición del modelo iconográfico de la Virgen de Chiquinquirá21.

2.2. El Milagro de la Renovación. Completando la nómina de personajes

En la leyenda asociada al milagro de la renovación del lienzo hay algunos personajes importantes que debemos atender para establecer las relaciones de vecindad de nuestro pintor en la ciudad de Tunja, entre ellos destacaría María Ramos, natural de Guadalcanal (Sevilla) y Catali- 
na García de Irlos, como ya hemos mencionado esposa de Antonio de Santana y parece ser que originaria también de la provincia sevillana.

Según la leyenda María Ramos llegó al Nuevo Reino de Granada acompañada de Francisco de Aguilar Santana para establecerse con su marido Pedro de Santana ${ }^{22}$, al que había ido a buscar23, pero tras el despecho sufrido por su infidelidad fue a parar a Chiquinquirá. Allí se estableció con Catalina García de Irlos, encomendera del pueblo, cargo que había ocupado desde la muerte de su esposo. A ambas las unían razones de parentesco, no obstante, en un interrogatorio al que someten a María años después y que trataremos más adelante, la razón principal de vivir con Catalina la tomó por ser ambas viejas amigas, probablemente de su época en Sevilla.

El 10 de enero de 1587, pocos días después de haberse obrado el prodigio, en el que no nos vamos a detener, se organizó una comisión para tomar testimonio del suceso a sus principales testigos entre los que se encontraba María Ramos, la india Isabel, Juana de Santana o el padre Juan de Figueredo, cura de los pueblos de Chiquinquirá y de Suta. Según el relato de la primera sería ella junto a la india Isabel y Juana de Santana quienes levantarían el lienzo poniéndolo sobre el altar, este testimonio sería corroborado por las otras personas implicadas, destacando del interrogatorio a la propia Juana de Santana. El parentesco de esta no queda claro y lo único que hemos podido averiguar hasta el momento es que era viuda de un tal Juan Morillo y que también vivía en Chiquinquirá junto a otras mujeres de las que no refiere sus nombres ${ }^{24}$ (fig. 3 ).

\section{Devoción y representación de Nuestra Señora de Chiquinquirá. La propagación de su fama}

Si el Milagro de la Renovación se produjo a finales de 1586, dos años más tarde la imagen de Nuestra Señora de Chiquinquirá sería llevada a Tunja para ser sacada en procesión intentando buscar su intercesión para acabar con la epidemia de viruela que azotaba la ciudad. Durante estos factos religiosos estuvo presente Juan de Castellanos, cronista que ejercía de párroco en la Iglesia de Santiago, quien sería fiel devoto de esta

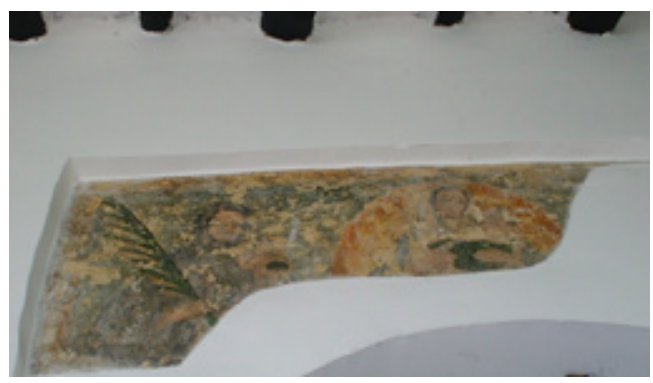

Fig. 4. Anónimo. Nuestra Señora de Chiquinquirá, segunda mitad siglo XVI. Casa del Fundador Gonzalo Suárez Rendón, Tunja, Departamento de Boyacá, Colombia. Fotografía: autora

advocación concediéndole poderes curativos. En 1601 Castellanos escribía25:

\section{Cae Chiquinquirá más adelante, poblezuelo de muy poco momento, ahora celebrado grandemente a causa del retrato venerable, imagen de la Virgen sin mancilla por cuya intercesión alli se muestra el Sumo Hacedor Maravilloso sanando ciegos, mancos y tullidos.}

La devoción hacia la Virgen de Chiquinquirá y la propagación de su fama de milagrosa ya estaba muy extendida para estas fechas como explica el propio Castellanos en 1588 cuando afirma que «los caciques que tenían pueblos algo más apartados del camino, rogaban la pasasen [la imagen] por sus casas prometiendo magníficas limosnas» ${ }^{26}$. De hecho, casi con toda probabilidad muy poco tiempo después del milagro primigenio se comenzaron a realizar copias del lienzo o interpretaciones del mismo pues sabemos que su devoción se extendió pronto a otros lugares como Popayán, Quito o Lima. Así, la representación más antigua localizada hasta el momento data precisamente de la segunda mitad del siglo XVI localizándose en la casa del Fundador Gonzalo Suárez Rendón en Tunja, en el lateral derecho de la Iglesia Mayor de la ciudad hacia la plaza principal. Se trata de un mural, muy deteriorado, situado en la parte alta de la pared sobre un arco de medio punto que da acceso a la sala principal de la vivienda. De ella solo se conserva el tercio superior de las imágenes de San Antonio de Padua y de la Virgen, estando el resto de la composición prácticamente perdida ${ }^{27}$. Debido a 


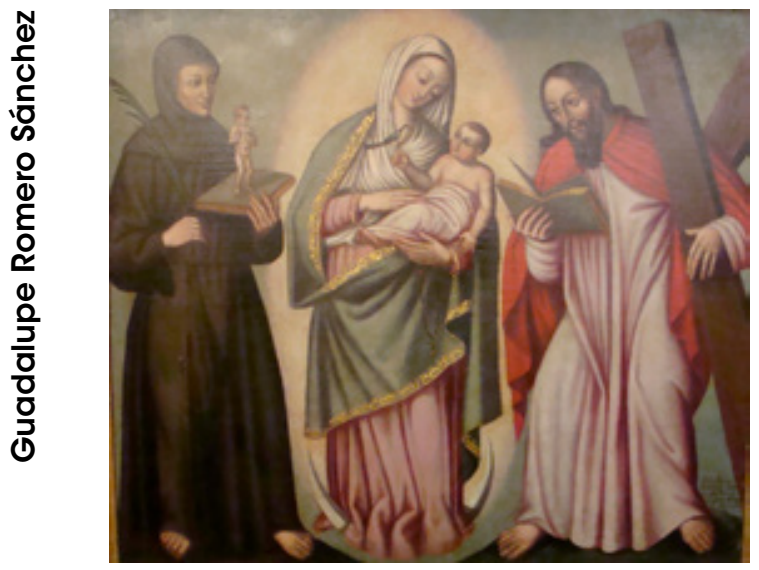

Fig. 5. Acero de la Cruz, Antonio. Nuestra Señora de Chiquinquirá, 1643. Basílica de Nuestra Señora del Rosario. Chiquinquirá, Departamento de Boyacá, Colombia. Fotografía: autora

su iconografía, antigüedad y ubicación algunos investigadores han dejado entrever la posibilidad de que esta obra sea también una creación de Alonso Narváez ${ }^{28}$, teoría que hasta el momento no tenemos datos para poder confirmar o desmentir aunque sería muy poco probable, mientras otros investigadores exponen la posibilidad de que fuera ejecutada por Angelino Medoro, fray Pedro Bedón o alguno de sus seguidores ${ }^{29}$ (fig. 4).

Las imágenes posteriores, ya de lienzo, datan del siglo XVII, exceptuando quizás la atribuida a Bernardo Bitti o a su círculo que puede fecharse en el último tercio del XVI. La más significativa la ejecutada por el pintor Antonio Acero de la Cruz en 1643 y conservada en el Museo de la Basílica de Nuestra Señora de Chiquinquirá. No obstante, hay indicios de que Acero de la Cruz pudo pintar otra copia 10 años antes para la iglesia de Fúquene pudiéndose tratar de la que menciona el inventario de bienes realizado por el oidor Gabriel de Carvajal en 1638 «Otra hechura en lienzo al óleo de Nuestra Señora de Chiquinquirá con su marco de madera» ${ }^{30}$. En cuanto a los grabados el más antiguo localizado es el que se reprodujo a mediados del XVII en la obra «El Desierto Prodigioso y Prodigio del Desierto» de Pedro Solís de Valenzuela, aunque también debemos mencionar por su importancia el efectuado por Benito de Miranda (fig. 5).
Todos estos datos nos llevan a confirmar que la propagación de su devoción fue muy temprana y casi coetánea al milagro de la renovación del lienzo, aunque por desventura no se hayan conservado apenas ejemplos pictóricos que así lo demuestre. No obstante, como contrapartida si hemos podido localizar algunas referencias documentales que nos permiten validar la realidad de la peregrinación constante a la iglesia de este pequeño pueblo de indios e incluso su culto de forma temprana en algunos de los poblados de naturales limítrofes, como queda atestiguado a través de las referencias seleccionadas.

El pueblo de Chiquinquirá estuvo encomendado desde tiempo atrás a Antonio de Santana, sin embargo y como ya advertimos, los indígenas allí agregados no estaban siendo bien adoctrinados y sus viviendas ni siquiera quedaban cerca de la iglesia donde se veneraba a esta milagrosa imagen. Por esta razón desde la Real Audiencia santafereña se enviaron diferentes inspecciones y se comisionó a algunos oidores para que realizaran los trabajos oportunos con el fin de reducir de nuevo a los naturales en unos terrenos más próximos al templo facilitando así las labores de evangelización. El problema se hace más evidente en 1595 cuando se aprecia que el terreno que se pretendía utilizar para este fin lo tenía en propiedad Gonzalo Gallegos, cura de Chiquinquirá, quien afirmaba habérselo comprado a Alonso de Rivera Santana, aunque luego las autoridades intentaron probar que el propio Antonio de Santana lo había regalado años atrás al templo y que Gallegos se había apropiado de él. Lejos de esta disputa de difícil solución, en las pesquisas que siguieron que versaban sobre el posible cambio de emplazamiento del pueblo, se alegó la inconveniencia de ejecutarlo pues, según se desprende del relato, este hecho causaría muchas perturbaciones a los indios, a los españoles y a otros devotos de la Virgen que acudían al templo para venerar la imagen. Así lo demuestran los siguientes fragmentos:

... del sitio y asiento de la yglesia de Nuestra Señora de Chiquinquirá poco más de dos mil pasos, un çerro en medio que es del asiento de la dicha yglesia, no se puede ver la poblaçión e de los españoles ni otras personas que vinieren a visitar la ymagen de 
Nuestra Señora y tienen novenas, no les puedan hazer daño... ${ }^{31}$.

... que los dichos indios estén más juntos al sitio de la yglesia de Nuestra Señora de Chiquinquirá para les administrar los Santos Sacramentos porque del uno al otro ay muy poca distancia y quando en esto reçibiera algún más benefiçio no se compensa con el daño que pueden recibir de las personas que vienen a visitar /1903v la dicha Santa Casa con las cabalgaduras que de necesidad a la dicha çercanía van a hazer ${ }^{32}$.

Más importante aún que la propia peregrinación al templo será la constatación de la existencia de otras copias de la imagen en algunos de los pueblos de indios neogranadinos, uno de estos casos es el Sámaca donde el oidor Luis Henríquez realizó la inspección del templo el 22 de noviembre de 1599 afirmando la existencia de un «lienzo de Nuestra Señora de Chiquinquirá con San Francisco y San Andrés a los lados» ${ }^{33}$. Es obvio que hay un error en la descripción de la obra y confunde a San Antonio de Padua con San Francisco pero lejos de eso lo que nos interesa es la presencia real del cuadro que pudo haberse pintado varios años antes no pudiendo precisar la antigüedad del mismo. El hecho de poseer este templo doctrinero una imagen de este tipo a fines del siglo XVI corrobora la rápida difusión de su fama de milagrosa no solo entre la población española residente en Tunja o en Santafé sino entre los propios naturales reducidos en los pueblos cercanos.

Varios años más tarde, concretamente en 1636, el oidor Juan de Valcárcel realizó una nueva inspección a este templo constatando en esta ocasión la existencia todavía de este cuadro sobre el que afirma estar pintado al temple y adornado con un marco de madera dorado. Pero, lo que es más llamativo, es la existencia de otra «ymagen de bulto muy pequeña de Nuestra Señora de Chiquinquirá con San Andrés y San Antonio a los lados» ${ }^{34}$. Se trata de la única representación escultórica de esta advocación localizada hasta el momento, pudiéndose tratar de una imagen titular de alguna cofradía de naturales, lo que implicaría otros matices y análisis ${ }^{35}$.

Otro ejemplo temprano es el de Montambe inspeccionado por el oidor Diego Gómez de Mena el 11 de septiembre de 1600. Del inven- tario se extrae la existencia de una imagen «del retrato» de Nuestra Señora de Chiquinquirá que había donado Juan del Toro, encomendero de una de las parcialidades reducidas, para la doctrina, y dos mantas de algodón, una de las cuales servía de cielo y otra «está arrimada al çercado en que estaba puesta la ymagen de Nuestra Señora» la cual había sido donada por el encomendero del pueblo Juan de Ezpeleta. Estos datos llaman poderosamente la atención ya que se especifica claramente que la pintura era del retrato de Chiquinquirá lo que podría significar que se trataba de una copia fiel realizada del modelo original. Este tipo de reproducciones buscaban que los lienzos resultantes gozaran del mismo favor divino siendo consideradas igualmente como hacedoras de milagros, lo que implicaba su ocultación que bien podía hacerse con cortinas, como era lo habitual en estos casos, o/y con el añadido de un espacio acotado para resguardar la imagen e impedir el acceso a los devotos, como podía ocurrir aquí con la presencia del cercado.

Según nos expone Olga Acosta, «el cortinaje en los retratos de imágenes marianas se puede asociar con el velo, un elemento utilizado en la colocación de las Vírgenes milagrosas, cuyo uso se constituyó en una práctica corriente durante el periodo colonial en la Nueva Granada y, en general, en el Nuevo Mundo» ${ }^{36}$. A lo que se añade que además de servir para proteger del polvo y la luz, el velo tenía principalmente una función litúrgica en la presentación de las imágenes tanto en el ámbito sagrado como en el profano, dado que el cubrimiento y la develación de una imagen consistía una práctica fundamental en el culto a las imágenes. Las imágenes milagrosas solo en ocasiones especiales eran descubiertas, con ello se buscaba dosificar el efecto de la imagen sobre el espectador ${ }^{37}$.

Este efecto de la ocultación o inaccesibilidad lo apreciamos con la presencia del cercado en Montambe pero se observa de forma más rotunda en Susa. En este pueblo el oidor Gabriel de Carvajal fue el encargado de efectuar el inventario de bienes del templo el 14 de diciembre de 1638 y en su descripción dejó constancia de la existencia de los velos o de la previsión de su materialización, dejando entrever que se trataría de otra imagen copia fiel del retrato del Santuario o al menos 


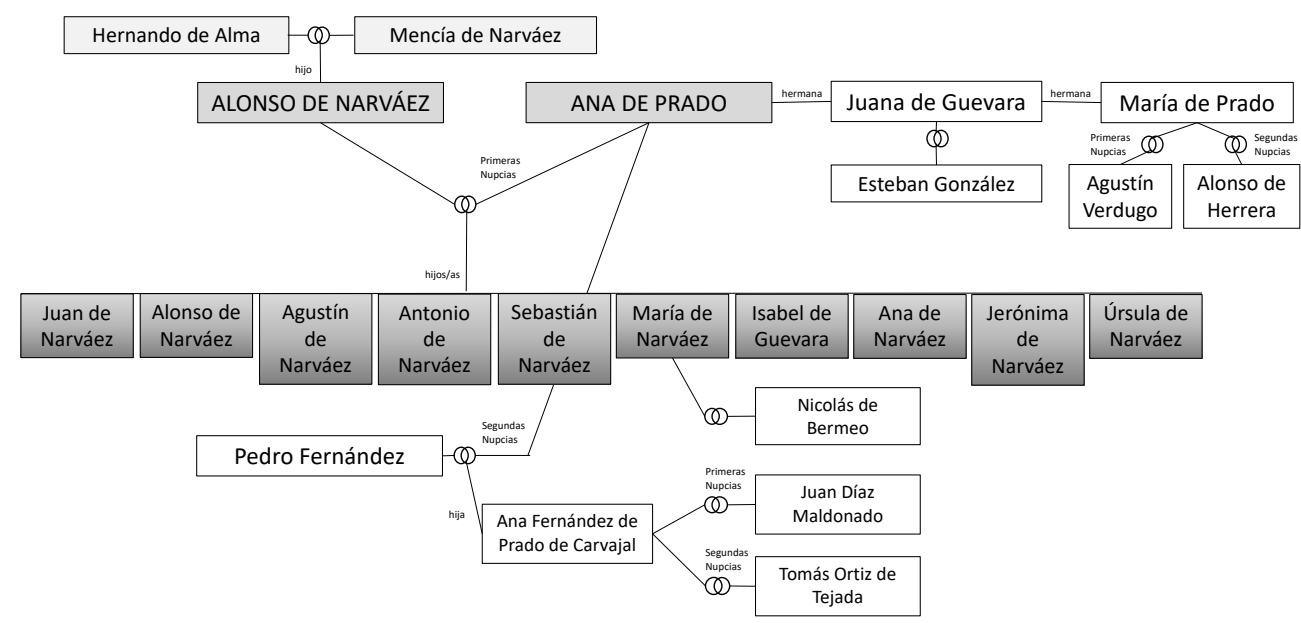

Fig. 6. Cuadro genealógico del pintor Alonso de Narváez y su mujer Ana de Prado. Elaboración propia

tocada al original que con los velos preservaría su fama:

Quatro varas y media de çintas de seda angosta para los velos de la ymagen de Nuestra Señora de Chiquinquirá que está en el altar desta iglesia ${ }^{38}$.

Otro lienzo pequeño al ólio de Nuestra Señora de Chiquinquirá guarnescido en madera y pintada de colorado, azul y amarillo, con dos velos viejos, el uno de tafetán colorado de la China y el otro de toca rajada ${ }^{39}$.

\section{Alonso de Narváez, artista sevillano en} la Tunja del siglo XVI. Nuevos aportes documentales a su biografía

Alonso de Narváez era hijo de Hernando de Alma y de Mencía de Narváez, natural de Alcalá de Guadaíra, desconociéndose la fecha en la que se establecería en la ciudad tunjana junto a su mujer Ana de Prado. Ambos tuvieron 10 hijos: Juan, Alonso, Agustín, Antonio, Sebastián, María, Isabel, Ana, Jerónima y Úrsula, todos referidos en el testamento del pintor ejecutado en 1583 con el apellido paterno excepto una de sus hijas a quien menciona como Isabel de Guevara ${ }^{40}$.

Los caminos entre los miembros de la familia de Alonso de Narváez y los de Antonio de Santana se cruzaron en varias ocasiones, así sabemos que por razones laborales nuestro pintor estu- vo vinculado también a la encomienda de Suta habiendo adquirido por concierto con Catalina García de Irlos los derechos de un molino que a la muerte de esta siguió siendo de su uso, disfrute y propiedad. Más tarde, en 1571, con motivo de las obras que se estaban realizando en la Iglesia Mayor de Tunja, se aprobó una segunda derrama $^{41}$ entre los vecinos para asumir la parte de los costes correspondientes, y es aquí donde sus nombres vuelven a coincidir. Alonso Narváez contribuiría como cualquier otro vecino con 2 pesos y 2 tomines y Antonio de Santana con 10 pesos y 4 tomines ${ }^{42}$.

Escasos datos sabemos en torno a los negocios y a la actividad de Narváez en Tunja. No obstante, podemos afirmar que Alonso de Narváez contaba con un pequeño taller probablemente en su domicilio y que estaba equipado con todos los utensilios propios de su oficio. También podemos atestiguar que tuvo varios encargos de obra, que pintó una botica para Pedro Hernández por valor de 50 pesos de oro corriente; que realizó dos crucifijos de 8 pesos del mismo valor para Pedro de Castro y María Hernández; que pintó tres lienzos de Nuestra Señora sin precisar advocación; dos hechuras de imágenes de la Virgen del retrato de San Lucas y el adorno de un retablo de grandes proporciones. Por otro lado mantuvo tratos con algunos mercaderes de la ciudad como demuestra la afirmación hecha en su testamento al dejar 
constancia de la cesión de una serie de pinturas a Francisco Hernández para su venta en su tienda o sus acuerdos con el carpintero Aranda, también residente en Tunja, a quien menciona varias veces en relación a vales firmados con é ${ }^{43}$.

Un contrato muy interesante que nunca llegó a cumplir por motivo de su muerte fue el realizado por Hernando de Lorenzana quien le encarga en 1583 la realización de dos imágenes de pasta, una de Nuestra Señora de la Soledad que debía ser igual que la existente en la iglesia mayor de Tunja y otra de Santa Lucía, las cuales serían de vestir y por la cuales recibiría 50 pesos de oro corriente. Con este documento queda patente que su actividad no se restringía solo a la pintura lo que abre muchísimo el abanico de otras obras de su autoría ${ }^{44}$.

Los últimos años de su vida fueron un poco más convulsos, así hemos podido saber que en 1580 se inicia una causa para intentar dilucidar si había habido engaño en un concierto establecido entre Lázaro de Alfaro con Alonso de Narváez y Nicolás de Bermeo, por el cual se comprometían a asumir 4000 pesos de una deuda contraída tiempo atrás entre Alfaro y Antonio de Santana, traspasándoles también todo el derecho que contra Santana tenían las escrituras originales.

Este interesante proceso saca a la luz primero que Nicolás de Bermeo, pintor de profesión, era el yerno de Narváez estando casado con su hija María y que ambos, o al menos así lo refieren, habían sido engañados por Alfaro, quien había mentido en la cifra de la deuda habiendo dolo en el concierto que piden anulen las justicias. La causa se complicó aún más pues Pedro de Santana, en nombre de Antonio fue quien solicitó traslado de las escrituras para sus propias investigaciones afirmando Bermeo que ellos las tenían ya reprobadas, solicitando que no se le diese copia de dichos documentos pues ninguno dejaba en buen lugar a Antonio de Santana, entendiéndose del contexto que el concierto con Alfaro lo habían hecho para proteger y ayudar a Santana, pudiéndoles unir, además de intereses laborales derivados de la encomienda de Suta, una relación de confianza o al menos de respeto ${ }^{45}$.

Para estas fechas los negocios de Narváez debieron marchar bien pues en los primeros años de 1580 el matrimonio adquirió unas casas en la ciudad de Tunja, de las que hablaremos más adelante, una de las cuales lindaba con la vivienda de Martín de Zerena y otra con la de la encomendera Catalina García de Irlos, ambos edificios habían pertenecido a Francisco Suárez de Mecina habiéndole pagado por ellas la cantidad de 870 pesos de oro corriente ${ }^{46}$.

Una vez fallecido Alonso de Narváez dejó como albaceas de su testamento ${ }^{47}$, por ser la mayoría de sus hijos menores de edad, a su mujer y a un tal Esteban González. Esta decisión acarreó numerosos problemas a su viuda debiendo gastar mucho dinero de la herencia en pleitos contra él ${ }^{48}$.

Estos pleitos, aportan informaciones interesantes. Así hemos podido averiguar que Esteban González era cuñado de Ana de Prado, que estaba casado con una hermana de ésta llamada Juana de Guevara, que tenía 30 años de edad en el momento de la sentencia y que era natural de las montañas de León llevando 16 años en Tunja. También hemos corroborado que en el momento de la muerte del pintor Ana de Prado debía tener 31 años de edad pues en la declaración del año 88 afirmaba tener 36, eso nos lleva a pensar que Narváez debió casarse con ella siendo ésta muy joven pues uno de sus hijos y probablemente el mayor, Juan, habría nacido cuando esta contaba tan solo con 13 años, afirmando a estas alturas tener 23. Otra hermana de Ana de Prado sería María de Prado, quien era tres años menor. María estuvo casada en primeras nupcias con Agustín Verdugo con quien tuvo varios hijos y tras el fallecimiento de éste contrajo matrimonio con Alonso de Herrera. Todos parecían vivir en la casa de su primer marido, al menos durante un tiempo, la cual lindaba con las Calles Reales y con la vivienda de Hernando de Almonte, pues posteriormente se mudarían. Entre ambas hermanas debieron existir problemas al saberse que su cuñado, Esteban González, le había dado 1000 pesos de oro de veinte quilates como parte del censo para su casa, reclamando Ana de Prado que ese dinero no era de González sino que era de la herencia de sus hijos de los que recordemos era curador no dueño, que procedía de una deuda mayor que tenía contraída con ellos Catalina García de Irlos y que él se había encargado de cobrar, desviando el dinero, siendo una de las causas iniciales del pleito entre ambos ${ }^{49}$ (fig. 6). 

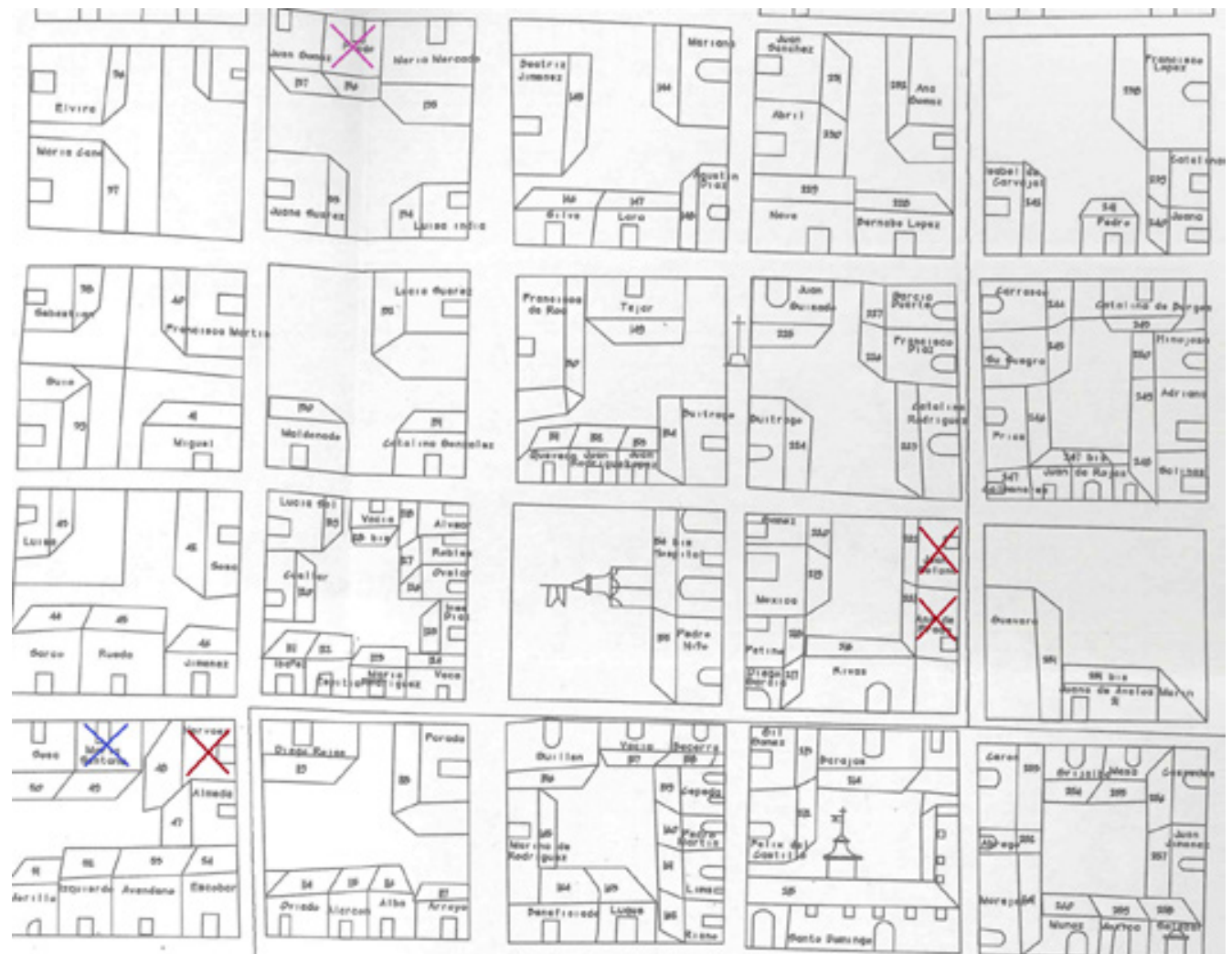

$=\operatorname{lin}_{-1}$
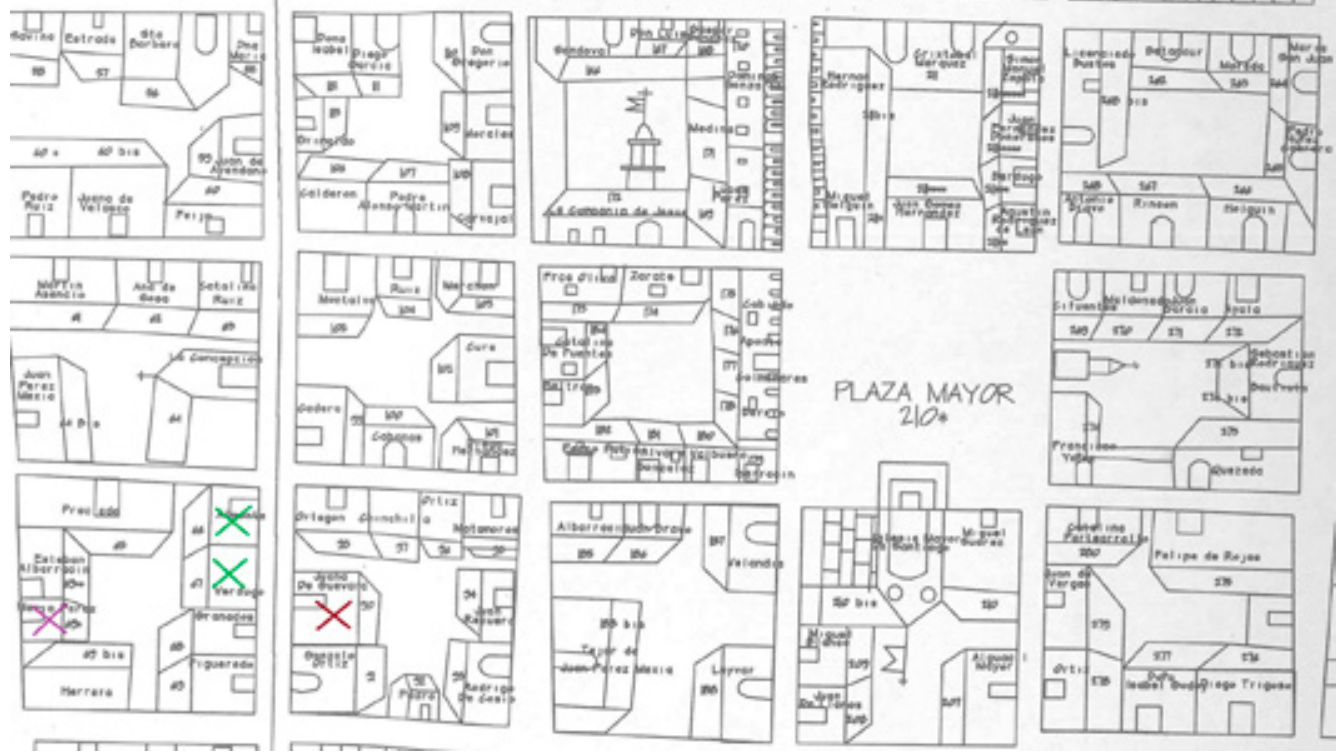

Fig. 7. Ubicación general de las casas identificadas. Detalle del plano elaborado en 2009 por Magdalena Corradine Mora en base al original de 1623. En él se identifican por manzanas las casas de Ana de Prado y Juan Solano, las casas de Juana de Guevara Almonte, Verdugo y María Pérez y las de Narváez y María Santana 


\section{Relaciones de vecindad. Identificación de personajes en el censo de población y sus residencias}

Una vez relacionados los personajes principales y sus vínculos con Alonso de Narváez vamos a identificar sus viviendas en Tunja y sus relaciones de vecindad. Para ello vamos a servirnos del interesante trabajo realizado por Magdalena Corradine Mora sobre el plano original de la ciudad de 1623, que digitaliza y también de los censos de 1620 y 1623: Memoria de los vecinos y moradores que ay en esta çiudad de Tunja y en todas las quadras y casas dellas (en adelante Memoria) y Memoria de las quadras, casas y vecinos que tiene la çiudad de Tunja conforme a las parrochias que se an de hazer (en adelante Relación), respectivamente ${ }^{50}$.

En el plano de 1623 (ver fig. 7) hay dos cuadras separadas por espacio de tres calles que nos llaman poderosamente la atención, en una de ellas se detalla como propietarios de los edificios de la manzana a Ana de Prado, que por este entonces contaría con 71 años, Juan Solano, Rivas, Diego García, Patino51, Moxica y Gómez; en la segunda hay una vivienda que se señala con el nombre de Narváez, siendo el resto de vecinos Sosa, María Santana, Almeda, Escobar, Avendano ${ }^{52}$, Izquierdo y Morillo. En el resto de la ciudad hay otras dos propiedades que nos interesan, una casa perteneciente a Juana de Guevara y otra distante a varias manzanas de ésta donde se menciona a Prado como su dueño o dueña.

Cuando consultamos la Memoria de 1620 nos percatamos de que la parcela identificada tanto en el plano como en la Relación como de Ana de Prado aquí figura con el nombre de Tomás Ortiz, quien sería el cabeza de familia en este momento. De tratarse de una de las casas adquirida en vida de nuestro pintor debió de ser la que lindaba con un tal Martín de Zerena, sin embargo, ninguna de las propiedades limítrofes llevan este nombre lo que nos impide poder identificarla como tal, a pesar de ello, nos decantamos por pensar que la vivienda era propiedad de Ana de Prado y no de Tomás Ortiz como refieren los documentos posteriores. Lo que está confirmado es que ella residía en esta casa en compañía de su hija Ana Fernández de Prado de Carvajal casada en primeras nupcias con Juan Díaz Maldonado y que tras el abandono de este vuelve a contraer matrimonio en 1598 con el mencionado Tomás Ortiz de Tejeda doce años más tarde ${ }^{53}$. Sobre su madre solo se menciona que en ese momento era viuda de un tal Pedro Fernández, por lo que atestiguamos que también ella volvió a casarse siendo Ana Fernández probablemente hija de este matrimonio. Si esta propiedad era fruto de la herencia de Alonso de Narváez o de Pedro Fernández es un dato que por el momento no podemos aclarar, lo que si podemos afirmar es que en la casa vivían otras ocho personas además de ellos, pudiendo ser cinco de ellos los hijos del matrimonio principal o del cabeza de familia llamados Lucas de Tejeda, Julio de Tejeda, Juan Ortiz, Pedro de Tejeda y Juan de Tejeda y dos indios de su servicio al no llevar apellidos y referenciarlos solo como Juliana y Pedro.

La vivienda de Tomás Ortiz lindaba como sabemos con la de Juan Solano, al comprobar el Memorial nos percatamos de que la mujer de este era una tal María de Prado, quien probablemente estuviera emparentada con Ana de Prado pudiendo tratarse de una de sus hermanas aunque de ser así Juan Solano sería su tercer marido. Al referenciarse en la nómina de personas residentes en esta casa otras dos personas homónimas nos inclinamos a pensar que, como ocurriera con Ana de Prado, su hermana viviera con una de sus hijas llamada igual que ella, con su yerno y con sus nietos, por tanto la dueña de la casa sería su sobrina no su hermana. En total vivían 26 personas en esta casa siendo una tercera parte de ellos indios e indias de servicio.

Como ya avanzamos, María de Prado se había casado en primeras nupcias con Agustín Verdugo cuya casa lindaba con la de Hernando de Almonte. Al comprobar el Memorial y el Plano nos percatamos de que hay una cuadra donde aparecen ambos nombres en casas limítrofes. La vivienda 66 seguiría perteneciendo a Almonte, sastre de 74 años y la marcada con el número 67 a un tal Francisco Verdugo Briceño de 44, mayordomo de la Cofradía de Nuestra Señora del Rosario, pudiendo tratarse de uno de los hijos de Agustín Verdugo y no sabemos de si también de María de Prado.

De las hermanas identificadas nos queda Juana de Guevara quien fuera mujer de Esteban Gonzá- 
lez y del que se había separado ante el Tribunal Eclesiástico ${ }^{54}$, al parecer no había tenido hijos y vivía sola junto a tres indias llamadas Pascuala, Beatriz y Laorcana, su casa distaba varias manzanas de la residencia de Ana, aunque quedaría casi enfrente de la vivienda de Francisco Verdugo, donde viviera su otra hermana anteriormente.

La casa identificada como de María de Narváez es una de las más interesantes, ella era la esposa de Nicolás de Bermeo, quien a estas alturas ya había muerto en los reinos del Perú. En la casa vivía, además de con el personal, con su hermana Isabel de Guevara y con una tal Marcela de Narváez de la que no hemos podido identificar el parentesco. Esta vivienda podemos confirmar que se trataría de una de las adquiridas por el matrimonio Narváez-Prado limítrofe con la casa de la encomendera Catalina García de Irlos que a estas alturas habitaba María de Santana una de sus descendientes.

Otras casas donde con un porcentaje alto de probabilidad residían otros miembros de la familia de nuestro pintor era la 69, perteneciente a María Pérez, viuda de Juan García de Prado, donde vivían también Francisca y Magdalena de Prado; y la 136 propiedad de Antonio de Prado que al parecer estaba casado con Antonia Suárez y quien tenía tres hijos: Ana Suárez, Gregoria de Prado y Josefa de Prado. De ellos no hemos podido establecer el parentesco pero sin duda debieron ser hijos, sobrinos o nietos del pintor (fig. 7).

\section{Conclusiones}

Las referencias familiares del pintor Alonso de Narváez que se desprenden de este estudio las entendemos cruciales para poder profundizar en un futuro sobre su vida y obra. Debemos tener en cuenta que este artista sevillano es aún muy desconocido en la historia del arte iberoamericano y que su importancia es superlativa, pues se trata del primer pintor establecido en el Nuevo Reino de Granada y autor del famoso cuadro de Nuestra Señora de Chiquinquirá. A través de esta investigación podemos corroborar también que una importante comunidad sevillana se estableció en la ciudad de Tunja en el siglo XVI y que entre ellos fijaron relaciones de vecindad y de trabajo. La nómina de personajes es muy amplia, no obstante, por el análisis que desarrollamos nos hemos centrado en dos de las personalidades más importantes como fueron el propio artista y Antonio de Santana, con su amplia familia. Sus viviendas, situadas muy cerca de la plaza mayor de la ciudad y de la Iglesia de la Compañía de Jesús, se encuentran muy próximas entre sí y su ubicación coincide, como hemos visto, con los datos aportados por el testamento de Narváez. De esta manera podemos establecer el lugar donde se estableció su taller y su área de actividad.

Por otro lado, gracias a este análisis hemos podido recrear su árbol genealógico, lo cual no era una tarea fácil pues los datos documentales estaban muy dispersos en varios archivos, aportando numerosos datos inéditos que amplían sobre manera el conocimiento de la biografía de este artista, gracias a ello hemos podido relacionar también a Narváez con Nicolás de Bermeo, también artista, quien además fue su yerno, con el que hemos constatado que colaboró en alguna ocasión. Sentamos las bases, pues, para avanzar en el conocimiento de este relevante pintor a nivel biográfico, lo que permitirá, gracias a las relaciones de vecindad y asentamiento en Tunja, profundizar en la posible identificación de su obra. 
NOTAS

1 Morales Folguera, José Miguel. 1998. Tunja. Atenas del Renacimiento en el Nuevo Reino de Granada. Málaga: Servicio de Publicaciones de la Universidad.

2 En esta época es reseñable la aparición de diversas imágenes milagrosas locales como por ejemplo Nuestra Señora de Monguí, el Cristo de Sopó, la Virgen del Rosario de Guaca o el San Juan de Sahagún, que se unen a la Virgen de Chiquinquirá, cuya fama y devoción pronto traspasará los límites de la Audiencia neogranadina.

${ }^{3}$ Mateus Rosada, Gustavo. 1989. Tunja. El arte de los siglos XVI-XVII-XVIII. Bogotá: Litografía Arco, s.p.

4 Vargas Murcia, Laura Liliana (2012). Del pincel al papel: Fuentes para el estudio de la pintura en el Nuevo Reino de Granada (1552-1813). Bogotá: ICANH, 32-33.

${ }^{5}$ Medoro con quien coincidiría largos años en Tunja llegaría a decir de Narváez: «La Virgen del mío caro amigo sobrevivirá todas las tempestades de la época y aún llegará a lejanas centurias, cuando habrán desaparecido las vírgenes de la faz de la tierra». Aristizábal, Luis H. 1987. "La Tunja de Inés de Hinojosa y de Juan de Castellanos". Boletín Cultural y Bibliográfico 13: 67.

${ }^{6}$ Romero Sánchez, Guadalupe. 2011. "Alonso de Narváez, pintor andaluz establecido en Tunja". In Andalucía y América. Patrimonio artístico, editado por Rafael López Guzmán, 13-30. Granada: Editorial de la Universidad.

7 Tobar y Buendía, Pedro de. 1986. Verdadera Histórica Relación del Origen, Manifestación y Prodigiosa Renovación por sí misma y milagros de la imagen de la Sacratísima Virgen María, Madre de Dios, Nuestra Señora del Rosario de Chiquinquirá, edición facsimilar de la impresión de Madrid de 1694. Bogotá: Instituto Caro y Cuervo.

${ }^{8}$ Tobar y Buendía y otros, Pedro de. 1986. La Virgen de Chiquinquirá. Única fuente histórica del milagro, escrita en el siglo XVII por el padre Pedro Tobar y Buendía. Colombia: Academia Boyacense de Historia y Caja Cultural Cooperativa, 43.
9 Flórez de Ocáriz, Juan. 1990. Libro primero de las Genealogías del Nuevo Reino de Granada, edición facsimilar de la impresión de Madrid de 1674. Bogotá: Instituto Caro y Cuervo e Instituto Colombiano de Cultura Hispánica, 7475.

${ }^{10}$ Los revenderos padres Cornejo y Mesanza se refieren a él con el nombre de Francisco Rivera Santana, si bien sabemos que se trata de otro de los sobrinos de Antonio de Santana quien participaría también de sus negocios y quien viviría en Chiquinquirá pero que no heredaría las encomiendas tras el fallecimiento de su esposa. Cornejo, Fr. José María y Mesanza, Fr. Andrés. 1919. Historia de la milagrosa imagen de Nuestra Señora del Rosario de Chiquinquirá, de su ciudad y su convento. Bogotá: Editorial Centro S.A., 27.

${ }^{11}$ Según refiere Magdalena Corradine Mora, Antonio de Santana dejaría un hijo natural del que no hemos podido encontrar ninguna otra referencia. Corradine Mora, Magdalena. 2008. Los fundadores de Tunja. Genealogías, Tomo I. Tunja: Academia Boyacense de Historia, 89.

${ }^{12}$ Vences Vidal, Magdalena. 2008. La Virgen de Chiquinquirá, Colombia: afirmación dogmática y frente de identidad. México: Museo de la Basílica de Guadalupe, 36.

${ }^{13}$ Archivo General de la Nación (AGN), Bogotá, Visitas Boyacá, Sección Colonia 62, tomo 18, folios 201r-201v. Este interrogatorio es muy interesante pues queda en evidencia la falta de doctrina a los indios reducidos en él siendo el propio Santana quien confiesa que no ha podido cumplir con su obligación de proporcionar cura o sacerdote para la evangelización de los naturales sencillamente por no haber hallado ninguno. Sobre esta cuestión se realizarán los informes con el cargo a la Audiencia para que esta actuara en consecuencia por el incumplimiento del encomendero ya que según parece con la anterior encomendera, la mujer de un tal Cristóbal de Roa, sí la había habido siendo la excusa de Santana al parecer falsa.

${ }^{14}$ Sastoque Poveda, Fr. Luis Francisco O.P. (s.f.). Historia de Nuestra Señora del Rosario, Chiquinquirá. Bogotá: Universidad Santo Tomás, 5.
${ }^{15}$ Zamora, Fr. Alonso de. 1980. Historia de la Provincia de San Antonino del Nuevo Reino de Granada. Bogotá: Instituto Colombiano de Cultura Hispánica, 22.

${ }^{16}$ Sobre el análisis de la iconografía ver: Romero Sánchez, Guadalupe. 2011. "Alonso de Narváez, pintor andaluz establecido en Tunja". In Andalucía y América. Patrimonio artístico, edited by Rafael López Guzmán, 13-30. Granada: Editorial de la Universidad.

${ }^{17}$ Este asunto es todavía elemento de debate pues se presupone que la manta facilitada por el encomendero y que usaría Narváez para su cuadro era más ancha que larga y que al pintar de manera apaisada a Nuestra Señora en el centro quedaron dos amplios espacios en blanco a los lados por lo que fue necesario completar la obra con la adición de dos santos que se dispondrían a ambos lados de la Virgen, interpretación simplista de la configuración de su iconografía ya advertida por Francisco Gil Tovar en sus estudios. El investigador sugiere que en realidad esta decisión se corresponde más a una yuxtaposición de figuras frontales en concordancia con la óptica medieval. Gil Tovar, Francisco. 1986. "La Virgen de Chiquinquirá en el arte". In Chiquinquirá. 400 años, edited by Octavio Arizmendi Posada et al., 167-95. Bogotá: Fondo Cultural Cafetero y Federación Nacional de Cafeteros, 83.

${ }^{18}$ Entre ellos errores de composición, al invertir el orden de ubicación de los santos pues en atención a su categoría deberían estar ejecutados San Andrés Apóstol a la derecha de la Virgen y San Antonio de Padua a la izquierda, y de iconografía siendo el más destacado la duplicidad del Niño Jesús o la advertencia de la palma del martirio que sostiene San Antonio, quien al no ser mártir no le correspondería este atributo, esta cuestión a veces ha sido solventada por algunos autores al hablar directamente de «un lirio en forma de palma» cuando describen al santo. Ariza, Fr. Alberto. 1986. Nuestra Señora de Chiquinquirá, Patrona Principal y Reina de Colombia. Bogotá, 28.

${ }^{19}$ Acosta Luna, Olga. 2011. Milagrosas imágenes marianas en el Nuevo 
Reino de Granada. Madrid-Frankfurt: Iberoamericana-Vervuert, 221.

${ }^{20}$ Romero Sánchez, Guadalupe. 2011. "Alonso de Narváez, pintor andaluz establecido en Tunja". In Andalucía y América. Patrimonio artístico, edited by Rafael López Guzmán, 13-30. Granada: Editorial de la Universidad.

${ }^{21}$ Fajardo de Rueda, Marta. 2014. "Grabados europeos y pintura en el Nuevo Reino de Granada". Historelo. Revista de historia regional y local, 6: 68-125; Vences Vidal, Magdalena. 2008. La Virgen de Chiquinquirá, Colombia: afirmación dogmática y frente de identidad. México: Museo de la Basílica de Guadalupe, 89 y Gil Tovar, Francisco. 1986. "La Virgen de Chiquinquirá en el arte". In Chiquinquirá. 400 años, edited by Octavio Arizmendi Posada et al., 167-95. Bogotá: Fondo Cultural Cafetero y Federación Nacional de Cafeteros, 85-86.

22 Probablemente otro hermano de Antonio de Santana o su sobrino.

${ }^{23}$ María Ramos según refieren otros autores tendría un parentesco diferente, para Álvarez White puede que se tratase de la esposa de un sobrino de Antonio de Santana habiendo llegado a Tunja en 1585, al año siguiente habría viajado a Chiquinquirá para dar el pésame a Catalina por la muerte de su esposo, fallecido años antes (Álvarez White, María Cecilia. 1986. Chiquinquirá, arte y milagro. Bogotá: Presidencia de la República y Museo de Arte Moderno, 14), para Flórez de Ocáriz, María Ramos era la cuñada de Francisco Aguilar de Santana y ésta además llevaría consigo en su periplo a su hija Felipa de los Reyes (Flórez de Ocáriz, Juan. 1990. Libro primero de las Genealogías del Nuevo Reino de Granada, edición facsimilar de la impresión de Madrid de 1674. Bogotá: Instituto Caro y Cuervo e Instituto Colombiano de Cultura Hispánica, 15).

${ }^{24}$ Arizmendi Posada et al., Octavio. 1986. Chiquinquirá. 400 años. Bogotá: Fondo Cultural Cafetero y Federación Nacional de Cafeteros, 29-35.

${ }^{25}$ Castellanos, Juan de. 1887. Historia del Nuevo Reino de Granada. Madrid: Imp. de Antonio Pérez Dubrull, 73.

${ }^{26}$ Acosta Luna, Olga. 2011. Milagrosas imágenes marianas en el Nuevo
Reino de Granada. Madrid-Frankfurt: Iberoamericana-Vervuert, 81.

${ }^{27}$ Sobre la posibilidad de que esta pintura mural fuera realizada en tiempos de Miguel Suárez de Figueroa, hijo mayor y heredero del fundador Gonzalo Suárez Rendón ver: Martínez Martín, Abel Fernando; Otálora Cascante, Andrés Ricardo y Espinoza Torres, María del Pilar. 2015. "En la ciudad de Dios. La advocación mariana de Miguel Suárez y las pinturas murales de la casa del fundador de Tunja Nuevos documentos e interpretaciones". Historia y Memoria 11: 179-211.

${ }^{28}$ Álvarez White, María Cecilia. 1986. Chiquinquirá, arte y milagro. Bogotá: Presidencia de la República y Museo de Arte Moderno, 31.

${ }^{29}$ Vences Vidal, Magdalena. 2008. La Virgen de Chiquinquirá, Colombia: afirmación dogmática y frente de identidad. México: Museo de la Basílica de Guadalupe, 169.

${ }^{30}$ AGN, Bogotá, Visitas Cundinamarca, Sección Colonia 62, tomo 6, folio $912 r$.

${ }^{31}$ AGN, Bogotá, Visitas Bolívar, Sección Colonia 62, tomo 5, folio 893v.

${ }^{32}$ AGN, Bogotá, Visitas Bolívar, Sección Colonia 62, tomo 5, folios 903r-903v.

${ }^{33}$ AGN, Bogotá, Visitas Boyacá, Sección Colonia 62, tomo 18, folio $721 \mathrm{v}$.

${ }^{34}$ AGN, Bogotá, Visitas Boyacá, Sección Colonia 62, tomo 18, folios 691 r y 693r.

${ }^{35}$ Romero Sánchez, Guadalupe. 2014. "Las congregaciones de indios en el territorio central de la audiencia de Nueva Granada, siglos XVI-XVII". In Devoción, Paisanaje e Identidad. Las cofradias y congregaciones de naturales en España y en América (siglos XVI-XIX), edited by Óscar Álvarez Gila, Alberto Angulo Morales y Jon Ander Ramos Martínez, 129-144. Bilbao: Universidad del País Vasco.

${ }^{36}$ Acosta Luna, Olga. 2011. Milagrosas imágenes marianas en el Nuevo Reino de Granada. Madrid-Frankfurt: Iberoamericana-Vervuert, 173.

${ }^{37}$ Stoichita, Víctor. 1996. El ojo místico. Pintura y visión religiosa en el siglo de Oro español. Madrid: Alianza Forma, 62.

${ }^{38}$ AGN, Bogotá, Visitas Cundinamarca, Sección Colonia 62, tomo 10 , folio 87 r.

${ }^{39}$ AGN, Bogotá, Visitas Cundinamarca, Sección Colonia 62, tomo 10 , folio 88 r.

${ }^{40}$ Romero Sánchez, Guadalupe. 2011. "Alonso de Narváez, pintor andaluz establecido en Tunja". In Andalucía y América. Patrimonio artístico, edited by Rafael López Guzmán, 13-30. Granada: Editorial de la Universidad, 17-18.

${ }^{41}$ La primera tuvo lugar en 1557 y la tercera en 1573 , constando en los documentos como uno de los contribuyentes de la primera carga Antonio de Santana.

${ }^{42}$ Porras Collantes, Ernesto. 2006. Corónica Colonial de Tunja y su provincia. Tunja: Academia Boyacense de Historia y Fondo Mixto de Cultura de Boyacá, 57, 65 y 67.

${ }^{43}$ Romero Sánchez, Guadalupe. 2011. "Alonso de Narváez, pintor andaluz establecido en Tunja". In Andalucía y América. Patrimonio artístico, edited by Rafael López Guzmán, 13-30. Granada: Editorial de la Universidad, 22-26.

${ }^{44}$ Archivo Histórico Regional (AHR), Tunja, Fondo Protocolo Notarial, volumen 11, año 1583, folios 381r.

${ }^{45} \mathrm{AGN}$, Bogotá, Fondo Historia Eclesiástica, Sección Colonia 30, documento 46, folios 773r-867v. En el folio 778 r se menciona a Alonso de Narváez como mercader.

${ }^{46}$ Romero Sánchez, Guadalupe. 2011. "Alonso de Narváez, pintor andaluz establecido en Tunja". In Andalucía y América. Patrimonio artístico, edited by Rafael López Guzmán, 13-30. Granada: Editorial de la Universidad, 19-20.

${ }^{47}$ AHR, Tunja, Fondo Protocolo Notarial, volumen 11, año 1583, folios 336r-342r.

${ }^{48}$ A González además se le abrieron numerosas causas judiciales resultando en 1588 una sentencia condenatoria por público difamador a servir 8 años en galeras debiendo partir al puerto de Cartagena de Indias y unirse como remo a una de sus flotas para una vez cumplida la pena regresar a España sin posibilidad de volver hacia América. 
AGN, Bogotá, Fondo Criminales (juicios), Sección Colonia 19, 151, documento 1, folios 30v-31r.

${ }^{49} \mathrm{AGN}$, Bogotá, Fondo Criminales (juicios), Sección Colonia 19, 151, documento 1.
${ }^{50}$ Corradine Mora, Magdalena. 2009. Vecinos y moradores de Tunja 1620-1623. Tunja: Consejo Editorial de Autores Boyacenses.

${ }^{51}$ Probablemente Patiño.

52 Posiblemente Avendaño.
${ }^{53}$ Corradine Mora, Magdalena. 2009. Vecinos y moradores de Tunja 1620-1623. Tunja: Consejo Editorial de Autores Boyacenses, 185.

${ }^{54}$ Corradine Mora, Magdalena. 2009. Vecinos y moradores de Tunja 1620-1623. Tunja: Consejo Editorial de Autores Boyacenses, 150. 


\section{REFERENCIAS}

Acosta Luna, Olga. 2011. Milagrosas imágenes marianas en el Nuevo Reino de Granada. Madrid-Frankfurt: Iberoamericana-Vervuert. https://doi.org/10.1080/10609164.2013.85 1355

Álvarez White, María Cecilia. 1986. Chiquinquirá, arte y milagro. Bogotá: Presidencia de la República y Museo de Arte Moderno.

Aristizábal, Luis H. 1987. "La Tunja de Inés de Hinojosa y de Juan de Castellanos." Boletín Cultural y Bibliográfico 13: 67.

Ariza, Fr. Alberto. 1986. Nuestra Señora de Chiquinquirá, Patrona Principal y Reina de Colombia. Bogotá.

Arizmendi Posada, Octavio, et al. 1986. Chiquinquirá. 400 años. Bogotá: Fondo Cultural Cafetero y Federación Nacional de Cafeteros.

Castellanos, Juan de. 1887. Historia del Nuevo Reino de Granada. Madrid: Imp. de Antonio Pérez Dubrull.

Cornejo, Fr. José María, y Fr. Andrés Mesanza. 1919. Historia de la milagrosa imagen de Nuestra Señora del Rosario de Chiquinquirá, de su ciudad y su convento. Bogotá: Editorial Centro S.A.

Corradine Mora, Magdalena. 2008. Los fundadores de Tunja. Genealogías, Tomo I. Tunja: Academia Boyacense de Historia.

Corradine Mora, Magdalena. 2009. Vecinos y moradores de Tunja 1620-1623. Tunja: Consejo Editorial de Autores Boyacenses.

Fajardo de Rueda, Marta. 2014. "Grabados europeos y pintura en el Nuevo Reino de Granada." Historelo. Revista de historia regional y local 6: 68-125. https://doi.org/10.15446/ historelo.v6n11.41977

Flórez de Ocáriz, Juan. 1990. Libro primero de las Genealogías del Nuevo Reino de Granada, edición facsimilar de la impresión de Madrid de 1674. Bogotá: Instituto Caro y Cuervo e Instituto Colombiano de Cultura Hispánica.

Gil Tovar, Francisco. 1986. "La Virgen de Chiquinquirá en el arte." In Chiquinquirá. 400 años, edited by Octavio Arizmendi Posada et al., 167-95. Bogotá: Fondo Cultural Cafetero y Federación Nacional de Cafeteros.

Martínez Martín, Abel Fernando, Otálora Cascante, Andrés Ricardo, y María del Pilar Espinoza Torres. 2015. "En la ciudad de Dios. La advocación mariana de Miguel Suárez y las pinturas murales de la casa del fundador de Tunja Nuevos documentos e interpretaciones." Historia y Memoria 11: 179-211. https:// doi.org/10.19053/20275137.3728

Mateus Rosada, Gustavo. 1989. Tunja. El arte de los siglos XVI-XVII-XVIII. Bogotá: Litografía Arco.

Morales Folguera, José Miguel. 1998. Tunja. Atenas del Renacimiento en el Nuevo Reino de Granada. Málaga: Servicio de Publicaciones de la Universidad.

Porras Collantes, Ernesto. 2006. Corónica Colonial de Tunja y su provincia. Tunja: Academia Boyacense de Historia y Fondo Mixto de Cultura de Boyacá.

Romero Sánchez, Guadalupe. 2011. "Alonso de Narváez, pintor andaluz establecido en Tunja." In Andalucía y América. Patrimonio artístico, edited by Rafael López Guzmán, 13-30. Granada: Editorial de la Universidad.

Romero Sánchez, Guadalupe. 2014. “Las congregaciones de indios en el territorio central de la audiencia de Nueva Granada, siglos XVIXVII." In Devoción, Paisanaje e Identidad. Las cofradías y congregaciones de naturales en España y en América (siglos XVI-XIX), edited by Óscar Álvarez Gila, Alberto Angulo Morales y Jon Ander Ramos Martínez, 129-144. Bilbao: Universidad del País Vasco.

Sastoque Poveda, Fr. Luis Francisco O.P. (s.f.). Historia de Nuestra Señora del Rosario, Chiquinquirá. Bogotá: Universidad Santo Tomás.

Stoichita, Víctor. 1996. El ojo místico. Pintura y visión religiosa en el siglo de Oro español. Madrid: Alianza Forma.

Tobar y Buendía, Pedro de, et al. 1986. La Virgen de Chiquinquirá. Única fuente histórica del milagro, escrita en el siglo XVII por el padre Pedro Tobar y Buendía. Colombia: Academia Boyacense de Historia y Caja Cultural Cooperativa. 
Tobar y Buendía, Pedro de. 1986. Verdadera Histórica Relación del Origen, Manifestación y Prodigiosa Renovación por sí misma y milagros de la imagen de la Sacratísima Virgen María, Madre de Dios, Nuestra Señora del Rosario de Chiquinquirá, edición facsimilar de la impresión de Madrid de 1694. Bogotá: Instituto Caro y Cuervo.

Vargas Murcia, Laura Liliana (2012). Del pincel al papel: Fuentes para el estudio de la pintura en el Nuevo Reino de Granada (1552-1813). Bogotá: ICANH.

Vences Vidal, Magdalena. 2008. La Virgen de Chiquinquirá, Colombia: afirmación dogmática y frente de identidad. México: Museo de la Basílica de Guadalupe.

Zamora, Fr. Alonso de. 1980. Historia de la Provincia de San Antonino del Nuevo Reino de Granada. Bogotá: Instituto Colombiano de Cultura Hispánica. 